EASTERLIN PARADOKSUNUN ALTERNATIF BİR YAKLAŞIMLA INCELENMESİ: PANEL KESIRLI POLINOMIYAL MODELLER

AN ALTERNATIVE APPROACH OF THE EASTERLIN PARADOX: PANEL FRACTIONAL POLYNOMIAL MODELS Şaban KIZILARSLAN", Duygu USTA"

Geliş Tarihi: 11.09.2020

Kabul Tarihi:22.11.2021

(Received) (Accepted)

ÖZ: Easterlin Paradoksu, gelir ile yaşam memnuniyeti arasında doğrusal - logaritmik bir ilişkinin olduğunu ifade etmektedir. Buna göre, gelir düzeyindeki artış, bireylerin yaşam memnuniyeti düzeyini başlangıçta arttırmakta ancak bir noktadan sonra bu etki sabitlenmektedir. Bu çalışmada Easterlin Paradoksu makro düzeyde ele alınmıştır. Bu amaçla geniş bir ülke grubundan oluşan heterojen bir veri setinden faydalanılmıştır. Paradoksta yer alan ilişki için en uygun fonksiyonel şekli belirlemek amacıyla, literatürde yer alan çalışmalardan farklı olarak özgün bir yöntem kullanılmıştır. Kesirli polinomiyal modeller olarak ifade edilen bu yöntem, fonksiyonel ilişkilerin yapısını belirlemek için, değişkenlerin tamsayı olmayan kuvvetlerinden faydalanmaktadır. Bu yöntem, geniş çaplı bir model kümesinden en uygun olanı belirleme avantajına sahiptir. Bu çalışmada kesirli polinomiyal modeller ile panel veri modelleri entegre edilerek kullanılmıştır. Elde edilen sonuçlara göre, yaşam memnuniyeti ile ekonomik büyüme arasında sigmoid yapıda, kübik - logaritmik bir ilişki bulunmaktadır. Buna göre, düşük ekonomik büyümeye sahip ülkelerde, gelirin yaşam memnuniyetine etkisi üssel olarak artarken, yüksek büyümeye sahip ülkelerde bu etki logaritmik yapıya benzer şekilde önce artış göstermekte, daha sonra bu artış etkisini kaybetmekte ancak sabit bir hale gelmemektedir. Dolayısıyla yüksek gelirli ülkelerde Easterlin Paradoksunun geçerli olması daha muhtemel olmakla birlikte, yine de tam olarak geçerli olduğu söylenemez. Klasik yöntemlerle elde edilen daha genel bulgulara karşılık, kesirli polinomiyal modellerin kullanımı, paradoksun geçerliliğine dair daha detaylı sonuçlar elde edilmesine olanak sağlamıştır.

Anahtar Kelimeler: Kesirli Polinomiyal Modeller, Easterlin Paradoksu, Yaşam Memnuniyeti

ABSTRACT: Easterlin Paradox states that there is a linear-logarithmic relationship between income and life satisfaction. Accordingly, the increase in income level increases the life satisfaction level of individuals at the beginning, but after a point this effect becomes stable. In this study, the Easterlin Paradox is discussed at the macro level. For this purpose, a heterogeneous data set consisting of a large group of countries was used. In order to determine the most appropriate functional form for the relationship in the paradox, a unique method was used, unlike the studies in the literature. Expressed as fractional

\footnotetext{
*Arş. Gör., Van Yüzüncü Y1l Üniversitesi, saban.kizilarslan@marmara.edu.tr, ORCID:0000-0003-1545-9597.

***Arş. Gör., Marmara Üniversitesi, duygu.usta@marmara.edu.tr, ORCID:0000-0002-71134570 .
} 
polynomial models, this method uses non-integer powers of variables to determine the structure of functional relationships. This method has the advantage of determining the best fit from a large set of models. In the study, fractional polynomial models were used by integrating panel data models. According to the results, there is a sigmoid, cubiclogarithmic relationship between life satisfaction and economic growth. Accordingly, in countries with low economic growth, while the effect of income on life satisfaction increases exponentially, in countries with high growth, this effect first increases similar to the logarithmic structure, then this increase loses its effect but does not become stable. So although the Easterlin Paradox is more likely to prevail in high-income countries, it cannot be said to be exactly valid. In contrast to the more general findings obtained by classical methods, the use of fractional polynomial models enabled more detailed results regarding the validity of the paradox.

Key Words: Fractional Polynomial Models, Easterlin Paradox, Life Satisfaction

\section{EXTENDENT ABSTRACT}

The aim of this study is to examine the validity of the Easterlin Paradox, which reveals the relationship between income and life satisfaction, at a macro level, with a unique method. Life satisfaction is a comprehensive concept that includes happiness. Individuals' happiness levels and life satisfaction are affected by many different factors. One of the most basic of these factors is the economy. Income level of individuals has both a direct and indirect effect on life satisfaction. Because basic needs such as shelter, security, etc., which determine life satisfaction, are directly related to income. Other concepts such as hobbies are also indirectly related to income in the process of self-completion.

Although the existence of the effect of income on life satisfaction is undeniable, whether this effect is permanent is the subject of research. In his pioneering work on this subject, Easterlin (1974) argued that this relationship is logarithmic. In other words, it is stated that income has an increasing effect on happiness up to a certain point, but after this point, this effect is fixed and income will not continue to increase happiness continuously. This situation is defined as Easterlin Paradox in the literature. In order to analyze whether the Easterlin Paradox is valid in different countries, many studies have been carried out at the micro and macro level. While some studies have proven the validity of the paradox, there are also studies that reach opposite conclusions.

In this study, Easterlin Paradox was examined in terms of functional structure. There are various implications regarding the functional structure of the relationship between income and life satisfaction. In previous studies, results were obtained that the relationship examined was linear and non-linear. For this reason, in order to determine the real functional structure of the relationship, a unique method was preferred, different from the methods used before. The mentioned method is fractional polynomial models. In polynomial models, nonlinear relationships are captured by adding the high-order powers of the independent variable or variables to the model. However, taking these powers only as integers has several disadvantages. To get rid of these disadvantages and to obtain more detailed models, fractional polynomial models have been proposed. These models are a more general version of the polynomial models, in which some non-integer powers of the variables are used along with the integer powers of the variables. In simulation studies, it 
was determined that using the $S=\{-2,-1,-0.5,0,0.5,1,2,3\}$ powers of the variables would be sufficient to capture the relationship structure. Here, the zero power actually refers to taking the natural logarithm of the variable. Thus, relationships with logarithmic structure are also captured. Although it is possible to add higher powers, it is stated that these powers do not contribute so much to the model and increase the estimation cost. When making a fractional polynomial transformation to a variable, it is decided which powers to use and which order model to use. A combination of repetitive powers is possible for a variable, and in this case the repetitive power is represented by the corresponding power of the variable, multiplied by the natural logarithm of the variable. After determining which degree a model will be used, model estimation is performed using the Maximum Likelihood method.

Panel data models were used together with fractional polynomial models in the study. Panel data are two-dimensional data that allow modeling of changes in units with respect to time. These data, which allow to examine both the differences between units and the variation with time, also have the advantage of using a higher number of observations. In panel data models, unit and/or time effects can be added to the model as fixed or random. By integrating both methods, it is ensured that the advantages of the two methods are used together.

In this study, Easterlin Paradox is discussed in macro scale. To examine the largest possible dataset, a large and heterogeneous country group of 100 countries is considered. In order to prevent the macroeconomic fluctuations caused by the 2008 crisis from causing deviations in estimating the relationship structure, the ten-year period between 2009 and 2018 after the crisis was examined. There are 924 observations in total in the unbalanced panel data set. The Life Ladder variable in the World Happiness Report was used to represent life satisfaction as the dependent variable in the study. This variable is collected through annual surveys to measure the happiness of individuals in many countries, and then country averages are calculated. As the main independent variable, the annual growth rate of GDP per capita representing the income level was taken and the model was supported with various control variables.

When the results of the study were examined, it was determined that the relationship between economic growth and life satisfaction was not linear. It was determined that the relationship examined was a cubic-logarithmic relationship in a sigmoid structure. Mathematically, the quadratic fractional polynomial model with the iterative third power of economic growth was found to be the most suitable model. Accordingly, it can be said that economic growth has an exponential effect on life satisfaction in low- and middle-income countries. In high-income countries, the acceleration of this effect is decreasing, but it is not stabilized and the increasing effect, albeit low, continues. In this case, it can be said that the Easterlin Paradox is more likely to be valid for countries with positive economic growth. However, when examined in detail, it has been determined that the relationship is not fully logarithmic, that is, the increasing effect of income on happiness starts to lose momentum after a point, but it is not fixed. 


\section{GíRíș}

Yaşam memnuniyeti en genel anlamıyla kişilerin hayatları hakkında hissettikleri mutluluk veya öznel iyi oluş olarak tanımlanabilir. Öznel kelimesinden kasıt kişinin tamamen kendi hayat tecrübelerine dayanması, iyi oluş ise kişinin olumlu hisler hissetmesi anlamına gelmektedir (Diener, 1984). Bu kavram bazı durumlarda mutluluk ile eş anlamda kullanılmakta, diğer durumlarda ise mutluluğu da kapsayan daha geniş bir kavram olarak ele alınmaktadır. Bireylerin mutluluklarını ve dolayısıyla yaşamlarından memnuniyet düzeylerini belirleyen pek çok etmen bulunmaktadır. Ekonomik açıdan ele alındığında, yaşam memnuniyetinin temel belirleyicisi gelirdir. Bireylerin gelir düzeyi yükseldikçe, temel ihtiyaçlarına ve isteklerine ulaşmaları kolaylaşmaktadır. Maslow'un (1943) İhtiyaçlar Hiyerarşisinde ilk basamaklarda yer alan güvenlik, barınma ve beslenme gibi temel ihtiyaçların karşılanmasında gelir anahtar bir role sahiptir. Hiyerarşinin daha üst basamaklarına doğru çıkıldıkça gelirin daha dolaylı bir role büründügü söylenebilir. Bu nedenle gelir düzeyinin yaşam memnuniyeti üzerinde doğrudan veya dolaylı olarak önemli bir etkisi bulunmaktadır.

Gelirin yaşam memnuniyet düzeyini belirlemedeki rolü yadsınamaz olmakla birlikte, bu etkinin sürekliliği tartışma konusudur. Çünkü bireylerin gelir düzeyindeki sürekli artışın, mutluluk düzeylerinde sürekli bir artışa neden olacağı varsayımının her zaman geçerli olduğunu söylemek zordur. Bu tartışma Easterlin (1974) tarafından yapılan öncü çalışma ile dikkat çekmiş ve pek çok çalışmaya konu olmuştur. Easterlin, ekonomik büyümenin mutluluk üzerindeki arttırıcı etkisinin sürekli olmadığını ortaya koymuştur. Buna göre bireylerin gelir düzeyi arttıkça mutluluk düzeyleri de buna bağlı olarak bir noktaya kadar artmakta, ancak daha sonra sabit kalmaktadır. Bu durum literatürde Easterlin Paradoksu olarak adlandırılmaktadır. Bu paradoks matematiksel olarak ele alındığında, gelir ile mutluluk ve dolayısıyla yaşam memnuniyeti arasındaki ilişkinin logaritmik bir yapıda olduğunu ifade etmektedir.

$\mathrm{Bu}$ çalışmada, Easterlin Paradoksunun makro düzeyde geçerli olup olmadığının belirlenmesi amaçlanmaktadır. Bu amaçla ülkelerin ekonomik büyüme oranları ve yaşam memnuniyeti düzeyleri ele alınmıştır. Çalışmada, farklı gelişmişlik düzeylerinde olan geniş bir ülke grubunun yıllık verilerinden elde edilen bir panel veri seti kullanılmaktadır. Paradoksun geçerliliğini sınamak amacıyla, önceki çalışmalarda yer alan klasik regresyon teknikleri yerine özgün bir yöntem kullanılmıştır. Kesirli polinomiyal modeller olarak adlandırılan bu yöntem, değişkenlerin tamsayı olmayan üstlerinden faydalanmakta ve hem doğrusal hem de eğrisel olması muhtemel ilişkiler için en uygun fonksiyonel şekli belirlemeye imkan vermektedir. Yöntemin bu özelliği, Easterlin Paradoksunda yer alan doğrusal - logaritmik ilişki varsayımının geçerliliğini test etmek için diğer yöntemlere göre avantaj sağlamaktadır. Ayrıca çalışmada kesirli polinomiyal 
modeller, panel veri modellerinin içine entegre edilerek kullanılmıştır. Böylece panel veri modellerinin geniş veri kullanımı, birimlere ait özelliklerin zamana göre değişimlerinin incelenebilmesi gibi avantajları kesirli polinomiyal modellerin matematiksel avantajları ile bir araya getirilmiştir. Sonuçta yakın geçmişteki dönem için, neredeyse küresel anlamda Easterlin Paradoksunun geçerliliğinin sınanması mümkün hale gelmiştir. Kullanılan yöntem, paradoksun farklı gelir düzeyleri için farklı etkileri ifade eden iki hipotezinin de aynı anda incelenmesine olanak tanımaktadır. Diğer bir deyişle, gelirin mutluluk üzerindeki etkisinin düşük gelir düzeyinde arttırıcı olurken, yüksek düzeyde sabit kalacağını ifade eden iki hipotez de bir arada incelenmiş ve geçerli olup olmadıkları ayrı ayrı yorumlanmıştır. $\mathrm{Bu}$ avantaj, önerilen özgün yöntemin paradoks literatürüne katkısını güçlendirmektedir. Ayrıca önerilen yöntem, bu çalışmada makro düzeyde ele alınan paradoksun, herhangi bir ülkenin bireyleri açısından geçerliliğini incelemek amacıyla yapılacak mikro ölçekteki çalışmalarda da kullanılmaya uygundur.

Çalışmanın devamında mutluluk ve yaşam memnuniyetinin gelir ile ilişkisine dair literatür taramasına yer verilmektedir. Ardından metodoloji bölümünde bu çalışmanın özgünlügünü oluşturan kesirli polinomiyal modellerin ve panel veri modellerinin detaylarına yer verilmiştir. Daha sonra çalışmada kullanılan veri seti ve değişkenler açıklanmış ve son olarak çalışmadan elde edilen bulgu ve sonuçlar paylaşılmıştır.

\section{LITERATÜR TARAMASI}

Yaşam memnuniyeti ile ilgili çalışmalar başlangıçta psikoloji ve felsefe alanında yapılmış olsa da, 20 yüzyıldan itibaren ekonomi alanında da bu kavramla ilgili çalışmalar yapılmaya başlanmıştır. Easterlin (1974), mutluluk ve gelir arasındaki ilişkiyi açıkladığı çalışması ile oldukça ses getirmiş ve bu çalışma sonrasında benzer çalışmalar yapılmaya başlanmıştır. Zamanla araştırmacılar farklı ülkeler ve farklı zamanlar için mutluluğun ekonomik faktörler ile ilişkisini araştırmışlardır (Frey \& Stutzer, 2002). Gelir ve mutluluk arasındaki korelasyon, ulusal gelir ve mutluluk puanları ortalamalarını kullanan kesitsel çalışmalarda veya böyle bir ilişkinin gücünü azaltabilecek eğitim, işsizlik ve diğer ılımlı faktörleri kontrol eden çalışmalarda genellikle zayıftır (Caporale, vd., 2009). Literatürde yer alan çalışmalar incelendiğinde, yaşam memnuniyetinin çoğunlukla sosyal ve demografik özelliklerle ilişkisinin ele alındığı çalışmaların olduğu, ekonomik göstergelerin olduğu çalışmalarda ise çoğunlukla gelir değişkeninin yaşam memnuniyeti ile ilişkisinin incelendiği görülmektedir. Easterlin (1974), yaptı̆̆ çalışmada Amerika'da genelde zengin kesimlerin fakir kesimlerden daha mutlu olduğunu, gelir ve mutluluk arasında pozitif bir ilişki olduğunu bu ilişkinin kısa dönemde daha kuvvetli uzun dönemde ise daha zayıf olduğunu, artan ekonomik büyüme ile memnuniyet düzeyinin belirli bir seviyeye kadar arttığını fakat daha 
sonra herhangi bir artış olmadığını ortaya koymuştur. Bu ilişkiye Easterlin Paradoksu adını vermiştir. Bu paradoks özellikle uzun dönem çalışmaları için geçerlidir. Oldukça ses getiren bu kavramdan sonra, başka ülkeler için de bu paradoksun geçerli olup olmadığını anlamak amacıyla pek çok ülke için farklı zamanlarda çalışmalar yapılmıştır. Blanchflower ve Oswald (2004) yaptıkları çalışmada sadece ABD'de değil aynı zamanda Büyük Britanya, Belçika ve Japonya'da, 1970'lerin başından 1990'ların sonlarına kadar geçen dönemde, giderek artan bir yaşam standardına rağmen, ortalama mutluluğun artmadığını hatta azaldığını göstermişler ve Easterlin paradoksunu teyit etmişlerdir. Frey ve Stutzer (2002), Dünya Mutluluk Veritabanından ve ABD Nüfus Sayımı Bürosu'ndan elde ettiği verileri kullanarak geniş bir ülke örneğinde benzer sonuçları elde etmiştir.

Stevenson ve Wolfers (2008), çalışmalarında Easterlin Paradoksunu tekrardan incelemiş, pek çok ülke ve bu ülkelere ait son verileri kullanarak kişi başına düşen GSYİH ile kişi başı ortalama öznel iyi oluş yani ortalama memnuniyet düzeyi arasında anlamlı pozitif bir ilişki olduğunu, kişi başına düşen GSYİH artmasının memnuniyet düzeyini arttırdığını ve Easterlin Paradoksunda bahsedildiği gibi herhangi bir doyum noktasından sonra değişmeyeceğinin kanıtlanamayacağını ortaya koymuşlardır. Analizlerinde okuyucunun uygun fonksiyonel formları görsel olarak değerlendirmesini sağlamak için iki değişkenli saçılma noktalarından ve parametrik olmayan regresyon tekniklerinden faydalanmışlar ve sıralı probit regresyon ile en küçük kareler yöntemlerini kullanmışlardır. Yorumlamaya yardımcı olması amacıyla normal en küçük kareler regresyon doğrusunu ve mutluluk dağılımının merkezi bir bölümünü gösteren kesitsel standart sapmayı kullanmışlardır. Bununla birlikte memnuniyet düzeyi için sıralı probit endeksi oluşturmuşlardır. Probit endeksi, ülke içi varyasyona göre ülkelerdeki ortalama mutluluk seviyelerindeki farklılıkları ölçmede oldukça yararlıdır. Ham verilerden farklı olarak, sıralı probit, kesitsel standart sapmaya göre refahta oldukça büyük farklılıklar olduğunu göstermektedir. Benzer şekilde, mutlak gelir yerine logaritmik gelirin kullanılması doğrusal-logaritmik ilişkisini vurgular.

Easterlin ve Angelescu (2009), Stevenson ve Wolfers (2008) çalışmasına cevap olarak, kişi başına düşen GSYIHH ile yaşam memnuniyeti arasındaki pozitif anlamlı ilişkinin sadece kısa vadeli olduğu durumlarda ortaya çıktığını, ülkenin gelir ve mutluluk eğilimi eğim katsayılarının daha uzun sürelerde hesaplanması durumunda paradoksun yeniden ortaya çıktığını ve kişi başına gelir ile yine anlamlı olmadığını yazmışlardır. Mutluluktaki gelişme ile kişi başına GSYH'nin uzun vadeli büyüme oranı arasında anlamlı bir ilişki yoktur. Bu durum, çalışmalarında ele alınan 17 gelişmiş, 9 gelişen ve 11 geçiş ülkesinden oluşan ülke grubu için geçerlidir. Olumlu bir ilişkiyi bildiren zaman serisi çalışmaları, makroekonomik koşullardaki dalgalanmalardan kaynaklanan mutluluğun ve gelirin artması ile kısa vadeli pozitif bir ilişkiyi göstermektedir. Veenhoven ve Dumludağ (2015) 
Aralı 2021 Cilt 23 Say 2 (533-550)

yaptıkları çalışmada mutluluğun zaman içindeki gelişimi, iktisatçıların mutlulukla ilgili çalışmalara yönelişi ve bu çalışmalarla ilgili kısıtlar üzerinde durmuşlardır. Köksal ve Şahin (2015) çalışmasında bireylerin mutlulukları üzerinde gelirin ve gelir karşılaştırmasının tek tek etkisi ve birlikte etkisinin belirlenmesi amacıyla hiyerarşik regresyon analizi kullanılmıştır. Analiz sonuçlarına göre, bireylerin başkalarına göre kendi refah düzeyi algısı yükseldikçe, gelirin mutluluk üzerindeki etkisi zayıflamaktadır. Bu bulgular, yüksek refah düzeyi algısı durumunda bile bireylerin mutlu olamadıklarını ortaya koyması açısından önemlidir. Çirkin ve Göksel (2016), çalışmalarında mutluluk ve yaşam doyumunun gelir başta olmak üzere çeşitli ekonomik sosyal ve demografik değişkenlerden nasıl etkilendiğini incelemişlerdir. Çalışma anket yöntemiyle elde edilen 2014 yılına ait verilerle yürütülmüş ve analizde sıralı probit yöntemi kullanılmıştır. Gelir seviyesinde meydana gelen artış kişinin mutlu olma olasıllı̆g üzerinde istatistiki olarak anlamlı değilken kişinin daha yüksek bir yaşam doyumu seviyesine sahip olma olasılı̆̆ 1 üzerinde istatistiki olarak anlamlıdır.

\section{METODOLOJI}

$\mathrm{Bu}$ çalışmada yaşam memnuniyeti ile gelir ilişkisinin fonksiyonel yapısını tespit etmek amaciyla kesirli polinomiyal regresyon modellerinden faydalanılmıştır. Makro düzeyde yapılan çalışma için panel veri seti oluşturulmuş ve kesirli polinomiyal modeller panel veri modellerinin içine entegre edilerek kullanılmıştır. Kesirli polinomiyal modellerin teorik yapısı aşağıda açıklanmış, ardından panel veri modellerine değinilmiştir.

\subsection{Kesirli Polinomiyal Modeller}

Polinomiyal modeller, bir veya daha fazla açıklayıcı değişkenin modelde yüksek tamsayılı kuvvetleriyle yer aldığı regresyon modelleridir. Örneğin iki değişken arasındaki ilişkinin karesel olduğu bilindiğinde, açıklayıcı değişkenin karesi de modele eklenir. Tek açıklayıcı değişkenli, k. dereceden bir regresyon modeli aşağıdaki gibi gösterilebilir:

$$
y_{i}=\beta_{0}+\beta_{1} x_{i}+\beta_{2} x_{i}^{2}+\cdots+\beta_{k} x_{i}^{k}+\varepsilon_{i}
$$

İki açıklayıcı değişkene sahip ve tüm değişkenlerin karesel formda olduğu tam polinomiyal model ise aşağıdaki gibidir:

$$
y_{i}=\beta_{0}+\beta_{1} x_{1 i}+\beta_{2} x_{2 i}+\beta_{11} x_{1 i}^{2}+\beta_{22} x_{2 i}^{2}+\beta_{12} x_{1 i} x_{2 i}+\varepsilon_{i}
$$

Daha yüksek dereceden modeller için gösterim benzer şekilde genellenebilir. Polinomiyal modeller, klasik regresyon modellerinin çoğunda yer alan doğrusallık kısıtlamasını kaldırma avantajına sahiptir. Ancak doğrusal modellere göre avantajlı olmalarına rağmen, polinomiyal modellerin bazı dezavantajları bulunmaktadır. Örneğin yarı logaritmik modellerde ilişkinin şekli tam $U$ veya ters $U$ olmaya zorlanmaktadır. Ayrıca yüksek dereceli polinomiyal modellerde yapay 
dalgalanmalar ve regresyon eğrisinin uçlarında son etkileri ortaya çıkmaktadır. Yine değişkenler arasındaki ilişkinin yapısında asimptotların var olması durumunda polinomiyal modeller başarılı sonuçlar vermemektedir (Royston \& Altman, 1995).

Polinomiyal modellerde yer alan dezavantajları ortadan kaldırmak amacıyla kesirli polinomiyal modeller önerilmiştir. Bu modeller, polinomiyal modellerin daha genelleştirilmiş bir halidir ve değişkenlerin tamsayı olmayan bazı kuvvetlerini de içermektedir. Modelin genel gösteriminden önce, bir değişken için kesirli polinomiyal dönüşümü tanımlamak gerekir. Sürekli ve pozitif değerli bir değişken için kesirli polinomiyal dönüşüm aşağıdaki gibi tanımlanır:

$$
X^{(p)}=\left\{\begin{array}{ll}
X^{p} & p \neq 0 \\
\ln X & p=0
\end{array} ; \quad p \in S=\{-2,-1,-0.5,0,0.5,1,2,3\}\right.
$$

Burada $p$ değeri değişken için kuvveti tanımlar, ancak $p=0$ olması durumunda değişkenin doğal logaritması alınır. Tanımlanan bu dönüşüm yardımıyla, birinci dereceden kesirli polinomiyal model (FP1) aşağıdaki gibi yazılabilir:

$$
y_{i}=\beta_{0}+\beta_{1} x_{i}^{(p)}
$$

Genelliği bozmadan, bir değişken için $\mathrm{m}$. dereceden kesirli polinomiyal dönüşüm; $p_{1} \leq p_{2} \leq \ldots \leq p_{m} ; p_{j} \in S=\{-2,-1,-0.5,0,0.5,1,2,3\} ; j=1,2, \ldots, m$ olmak üzere,

$$
X^{\left(p_{j}\right)}= \begin{cases}X^{p_{j}} & p \neq 0 \\ \ln X & p=0\end{cases}
$$

olarak tanımlanır. Bu dönüşüm yardımıyla, $\mathrm{m}$. dereceden, tek değişkenli bir kesirli polinomiyal modelin (FPm) genel gösterimi aşağıdaki gibi yapılabilir: $p_{0}=0$ ve $H_{0}(X)=1$ olmak üzere;

$$
H_{j}(X)= \begin{cases}X^{\left(p_{j}\right)}, & p_{j} \neq p_{j-1} \\ H_{j-1}(X) \ln X, & p_{j}=p_{j-1}\end{cases}
$$

olarak tanımlanır ve

$$
\boldsymbol{F P m}(X, p)=\sum_{j=0}^{m} \beta_{j} H_{j}(X), p=\left(p_{1}, p_{2}, \ldots, p_{m}\right)
$$


Aralık 2021 Cilt 23 Sayı 2 (533-550)

olarak gösterilir. Örneğin, tek değişkenli, üçüncü dereceden bir kesirli polinomiyal model için kuvvetler $p=(-0.5,3,3)$ olarak belirlenmişse, bu modelin açı hali aşağıdaki gibidir:

$$
y_{i}=\beta_{0}+\beta_{1} x_{i}^{-0.5}+\beta_{2} x_{i}^{3}+\beta_{3} x_{i}^{3} \ln x+\varepsilon_{i}
$$

Tanımlanan $\mathrm{S}$ kuvvet kümesine göre, bir değişken için birinci dereceden toplamda 8 adet kuvvet, yani dönüşüm dönüşüm mevcuttur. Genel dönüşüm formülüne göre ikinci dereceden bir kesirli polinomiyal dönüşümde, tekrar eden kuvvetlerle birlikte değişken için toplam 36 kuvvet bulunmaktadır. S kuvvet kümesi kübik en fazla kübik modelleri içerecek şekilde kısıtlanmıştır. Kuvvet kümesinin daha yüksek kuvvetlere genişletilmesi mümkündür ancak yapılan çalışmalarda, istisnai durumlar dışında daha geniş bir kuvvet kümesine gerek olmadığ tespit edilmiştir (Royston \& Altman, 1994; Royston \& Sauerbrei, 2008) Kesirli polinomiyal modellerin tahmini En Çok Olabilirlik Yöntemi kullanılarak yapılmaktadır. Model seçimi yapılırken, önce her bir derece için en iyi model tespit edilir. Burada "en iyi" ifadesi, en yüksek logaritmik olabilirlik oranına sahip modeli veya denk olarak;

$$
D=-2 * \log \_ \text {olabilirlik }
$$

şeklinde hesaplanan sapma değeri en düşük olan modeli göstermektedir (Royston \& Altman, 1994). Daha sonra her derecenin en iyi modelleri kendi arasında kıyaslanır. Bu noktada, düşük dereceden modelin, yüksek dereceden modeller içerisinde yuvalanmış olduğu dikkate alınarak, model seçiminde yuvalanmış modeller için F Testi prosedürü uygulanır. Böylece, önce değişkenin etkisinin anlamlılığ , ardından ilişkinin doğrusallığı, son aşamada ise ilişkinin karmaşıklık düzeyi test edilmiş olur. Benzer süreç daha yüksek dereceden modeller için de uygulanabilir (Ambler \& Royston, 2001). Negatif değerli değişkenlerde logaritmik dönüşüm uygulanamadığından, bu değişkenler için kesirli polinomiyal model tahmin edilmeden önce bir orijin kaydırma işlemi yapılmaktadır:

$$
x_{i}^{*}=x_{i}-x_{\min }+\delta
$$

Burada $x_{\text {min }}$, değiş̧kenin aldığı en düşük değeri, $\delta$ ise pozitif bir yuvarlama değeridir. Bu değer, değişkenin ardışık değerleri arasındaki en düşük fark olarak seçilebilir. Değişken bir sayma veri ise, bu değer 1 olarak alınabilir (Royston \& Sauerbrei, 2008).

Kesirli polinomiyal modeller, birden fazla bağımsız değişken içerebilir. Bu durumda, değişkenlerin en uygun kesirli polinomiyal dönüşümlerinin sirayla elde edildiği, model seçimi ise geriye doğru eleme yönteminin kullanıldığı yinelemeli bir algoritma önerilmiş̧ir (Sauerbrei \& Royston, 1999). 


\subsection{Panel Veri Modelleri}

Panel veri, çeşitli birimlerin belirli bir zaman dönemi içerisinde bir arada ele alındığ 1 veri biçimidir. Panel veri analizi, incelenen birimlere ait değişkenlerin ve bu değişkenler arasındaki ilişkilerin zamana göre değişimini incelemeye imkan tanır. Bu veri türü, birimler için ortak bir çıkarım yapılması ve daha fazla veriyle çalışılması gibi avantajlara sahiptir. Ele alınan her birim için aynı dönem olması koşuluyla, eşit sayıda zaman döneminin olması durumunda bu veri dengeli panel olarak adlandırılırken, birimlere ait zaman dönemi sayısının farklı olması durumunda veri dengesiz panel olarak adlandırılır. $\mathrm{N}$ birim ve $\mathrm{T}$ zaman dönemi içeren bir panel veri için, $\mathrm{k}$ açıklayıcı değişkene sahip panel regresyon modelinin genel gösterimi

$$
\mathrm{Y}_{\mathrm{it}}=\alpha_{i t}+\sum_{j=1}^{k} \beta_{j} X_{j i t}+u_{i t} ; \quad i=1,2, \ldots, N ; \quad t=1,2, \ldots, T
$$

şeklinde yapılabilir. Burada $i$ birimleri, $t$ ise zaman dönemini ifade etmektedir. Panel veri modellerinde, klasik regresyon modellerinden farklı olarak, birimler arasındaki farklılıklar ve/veya zamana göre değişimin etkisi modele dahil edilmektedir. Bu etkilerin modele dahil edilme biçimine göre iki farklı panel veri modeli bulunmaktadır. Birim etkisi üzerinden ifade edilecek olursa, birimlerden kaynaklı farklılıkların sabit olarak düşünüldüğü sabit etkili modelde, birim etkisi modelin sabit terimi içerisine dahil edilmektedir:

$$
\alpha_{i t}=\alpha+\mu_{i}
$$

Birimler arası farklılıkların tesadüfi bir değişken olarak ele alındığı tesadüfi etkili modelde ise birim etkisi, hata teriminin bir bileşeni olarak ele alınmaktadır:

$$
u_{i t}=\mu_{i}+\varepsilon_{i t}
$$

Burada $\mu_{i}$ birim etkisini ifade etmektedir. Sabit etkili modeller, birimlerin zamana göre ortalamalarından farklarının kullanıldığı Grup İçi Tahmin yöntemiyle tahmin edilirken, tesadüfi etkili modeller ise Genelleştirilmiş En Küçük Kareler veya En Çok Olabilirlik yöntemiyle tahmin edilebilir (Güriş \& Kızılarslan, 2018).

Çalışmada fonksiyonel ilişkinin yapısını belirlemek amacıyla, gelir değişkeni sabit ve tesadüfi panel veri modellerine kesirli polinomiyal dönüşümle dahil edilmiştir. Tek açıklayıcı değişkenin kesirli polinomiyal yapıda yer aldığı panel veri modeli aşağıdaki gibi gösterilebilir:

$$
\mathrm{Y}_{\mathrm{it}}=\alpha_{i t}+\operatorname{FPm}\left(X_{1 i t,} p\right)+\sum_{j=2}^{k} \beta_{j} X_{j i t}+u_{i t}
$$


Aralık 2021 Cilt 23 Sayı 2 (533-550)

Model tahmininde ve model seçiminde kesirli polinomiyal modellerin tahmin ve seçim süreci kullanılmıştır. Model seçimi logaritmik olabilirlik oranına dayalı olduğundan, tesadüfi etkili panel veri modelinin tahmininde bu oranın elde edilebildiği En Çok Olabilirlik yöntemi kullanılmıştır.

\section{VERI SETI VE DEĞİŞKENLER}

$\mathrm{Bu}$ çalışmada yaşam memnuniyetinin gelirle olan ilişkisinin yapısı makro düzeyde ele alınmıştır. Bu amaçla mümkün olan en geniş veri seti elde edilmeye çalışılmıştır. Çalışmada toplamda 100 ülke yer almaktadır. Zaman dönemi olarak 2009 - 2018 yıllarını içeren 10 yıllık dönem belirlenmiştir. 2008 küresel krizinden kaynaklı olarak, makro değişkenlerde ve özellikle ülkelerin ekonomik büyüme oranlarında bir yapısal kırılma gerçekleşmiştir. Bu yapısal kırılmanın tahmin edilen ilişki grafiğini etkilememesi için kırılma sonrası dönem ele alınmış ve verilere ulaşılabilen en son y1lı içeren dönem analize dahil edilmiştir. Elde edilen veri seti dengesiz bir paneldir ve 924 gözlemden oluşmaktadır.

Bağımlı değişken olarak yaşam memnuniyetini temsilen Dünya Mutluluk Raporu'nda yer alan "Yaşam Merdiveni (Life Ladder)" ölçüsü kullanılmıştır. Dünya Mutluluk Raporu, Gallup World Poll tarafindan yıllık olarak yayınlanan bir rapordur ve 150 'den fazla ülkede yapılan bir dizi anketin sonuçlarını içermektedir. Aynı içeriğe sahip olan bu anketler genellikle her ülkede binden fazla kişiye uygulanmaktadır. Birleşmiş Milletler Genel Sekreterliği tarafından görevlendirilen Sürdürülebilir Kalkınma Çözümleri Ağı, Dünya Mutluluk Raporu'nu küresel mutluluk düzeyinin temel anketi olarak kullanmaktadır. Yapılan anketlerde bireylere mutluluk düzeyini belirlemek için aşağıdaki soru sorulmaktadır:

"En alt basamağı 0, en üst basamağı 10 olarak numaralandırılmış bir merdiven hayal edin. Bu merdivenin en alt basamağı sizin için olabilecek en kötü yaşam düzeyini, en üst basamağı ise olabilecek en iyi yaşam düzeyini temsil etsin. Kendi yaşamınıza baktığınızda, kişisel olarak kendinizi merdivenin hangi basamağında hissediyorsunuz?"

Her ülke için soruya alınan cevapların ortalaması, o ülkenin ortalama mutluluk algı skoru olarak alınmaktadır. Böylece ilgili yıl için her ülkede yaşayan bireylerin ortalama mutluluk algı düzeyi elde edilmiş olmaktadır (World Happiness Report, 2019).

Çalışmada özellikle ilgilenen bağımsız değişken gelir değişkeni ve bu değişkenin fonksiyonel yapısıdır. Gelir değişkeni olarak kişi başına düşen Gayrı Safi Yurtiçi Hasıla'nın (GSYH) yıllık büyüme oranı kullanılmıştır. Ayrıca yaşam memnuniyeti literatüründe yer alan ve bu değişkeni etkilemesi muhtemel makro değişkenler modele bağımsız değişken olarak eklenmiştir. Bu kontrol değişkenleri devlet harcamaları, işsizlik ve cari işlemler dengesidir (CID). Bunlar dışında yine literatürde yer alan İnsani Gelişmişlik Endeksi, ortalama yaşam süresi, ortalama okullaşma yılı, eğitim süresi ve enflasyon gibi değişkenler de analize dahil 
edilmiştir. Ancak birim sayısının yüksek olmasından kaynaklı olarak panel veri seti heterojen bir yapıdadır. $\mathrm{Bu}$ nedenle, bu değişkenlerin incelenen dönemde tüm birimler için ortak ve istatistiksel olarak anlamlı bir etkisi olmadığı tespit edilmiş ve modelden çıkartılmışlardır. Bahsi geçen tüm bağımsız değişkenler Dünya Bankası veri tabanından elde edilmiştir. Tahmin edilen nihai model aşağıdaki gibidir:

$$
\text { Memnuniyet }_{i t}=\alpha_{i t}+F P m\left(G D P_{i t}, p\right)+\beta_{1} \text { Devlet }_{-} \text {Harc }_{i t}+\beta_{2} \dot{I}_{\text {Şsizlik }}{ }_{i t}+\beta_{3} C \dot{I D}_{i t}
$$

Çalışmanın bulguları bir sonraki bölümde sunulmuştur.

\section{BULGULAR}

$\mathrm{Bu}$ çalışmada yaşam memnuniyeti ile gelir arasındaki ilişkinin yapısı incelenmiştir. Çalışma makro düzeyde yapıldığından, gelir düzeyini temsilen ülkelerin ekonomik büyüme oranları kullanılmıştır. İlişkinin yapısını belirlemek amacıyla, bu değişkenin kesirli polinomiyal yapıda eklendiği sabit ve tesadüfi panel veri modelleri tahmin edilmiştir. Ardından modeller arasında seçim yapıldıktan sonra, uygun model için incelenen ilişkinin yapısı grafik üzerinden yorumlanmıştır. Sabit etkili kesirli polinomiyal panel veri modelinin sonuçları Tablo 1'de verilmiştir.

Tablo 1. Sabit Etkili Kesirli Polinomiyal Panel Veri Modeli

\begin{tabular}{|c|c|c|c|c|}
\hline \multicolumn{3}{|c|}{$\begin{array}{l}\text { Bağımlı Değişken: Memnuniyet } \\
\text { Gözlem Sayısı: } \quad 924\end{array}$} & \multicolumn{2}{|c|}{$\begin{array}{l}F(5,819)=22.33 \\
\text { Prob }>F=0.000\end{array}$} \\
\hline Değişken & Katsayı & Std. Hata & $\mathbf{t}$ & $\mathbf{P}>|\mathbf{t}|$ \\
\hline Sabit & 5.483 & 0.152 & 35.98 & 0.000 \\
\hline GDP^3 & 0.040 & 0.016 & 2.51 & 0.012 \\
\hline$\left(G^{\prime} P^{\wedge} 3\right)^{*} \ln G D P$ & -0.024 & 0.014 & -1.77 & 0.078 \\
\hline Devlet Harc. & 0.037 & 0.010 & 3.82 & 0.000 \\
\hline İşsizlik & -0.066 & 0.007 & -9.28 & 0.000 \\
\hline Cí & 0.006 & 0.003 & 2.18 & 0.030 \\
\hline F Testi $\mu_{i}=0$ & F $(99$ & 81.12 & & $>\mathrm{F}=0.000$ \\
\hline
\end{tabular}


Aralık 2021 Cilt 23 Sayı 2 (533-550)

Tablo 1 incelendiğinde, ilk satırda verilen $\mathrm{F}$ Testi sonucuna göre elde edilen modelin genel olarak anlamlı olduğu görülmektedir. Son satırda verilen F Testi ise modelde birim etkinin anlamlı olup olmadığını belirlemek amacıyla yapılmıştır. Test sonucunda anlamlı birim etkisi olmadığını ifade eden sıfır hipotezi reddedilmiş ve modelde birim etkilerin anlamlı olduğu tespit edilmiştir.

Modelde yer alan kontrol değişkenleri incelendiğinde, ele alınan üç değişkenin de istatistiksel olarak anlamlı bir etkiye sahip olduğu görülmektedir. Buna göre devlet harcamaları ve cari işlemler dengesi, ülkelerin ortalama yaşam memnuniyeti üzerinde pozitif bir etkiye sahipken, işsizlik ise negatif bir etkiye sahiptir. Bu sonuçlar literatürde yer alan sonuçlarla uyumludur.

Çalışmanın temel bağımsız değişken olan ekonomik büyüme değişkenine ait sonuçlar incelenecek olursa, ekonomik büyüme ile yaşam memnuniyeti arasındaki ilişkinin doğrusal olmadığı görülmektedir. Elde edilen en uygun kesirli polinomiyal model FP2(GDP,3,3) modelidir. Buna göre ekonomik büyüme ile yaşam memnuniyeti arasındaki ilişki kübik - logaritmik bir yapıdadır ve matematiksel olarak aşağıdaki gibi ifade edilebilir:

\section{Yaşam Memnuniyeti $=0.040 G D P^{3}-0.024 G D P^{3} * \ln G D P$}

$\mathrm{Bu}$ iliş̧kinin yapısı grafiksel olarak daha net anlaşılacağından Şekil 1'de verilen grafik üzerinden yorumlanacaktır. Grafik yorumu yapılmadan önce, tesadüfi etkili kesirli polinomiyal panel veri modelinin tahmin sonuçları ve model seçim sonuçları Tablo 2'de verilmiştir.

Tablo 2. Tesadüfi Etkili Kesirli Polinomiyal Panel Veri Modeli

\begin{tabular}{|c|c|c|c|c|}
\hline \multicolumn{3}{|c|}{$\begin{array}{l}\text { Bağımlı Değişken: } \\
\text { Gözlem Sayısı: }\end{array}$} & \multicolumn{2}{|c|}{$\begin{array}{l}\text { LR chi } 2(5)=115.05 \\
\text { Prob }>\text { chi2 }=0.000\end{array}$} \\
\hline Değişken & Katsayı & Std. Hata & $\mathbf{z}$ & $\mathbf{P}>|\mathbf{z}|$ \\
\hline Sabit & 5.225 & 0.176 & 29.60 & 0.000 \\
\hline GDP^3 & 0.043 & 0.016 & 2.68 & 0.007 \\
\hline$\left(\right.$ GDP^3$\left.^{\wedge}\right) * \operatorname{lnGDP}$ & -0.025 & 0.013 & -1.89 & 0.059 \\
\hline Devlet Harc. & 0.050 & 0.009 & 5.51 & 0.000 \\
\hline İşsizlik & -0.063 & 0.007 & -9.31 & 0.000 \\
\hline CID & 0.009 & 0.003 & 3.16 & 0.002 \\
\hline LR Testi $\sigma_{\mu}=\mathbf{0}$; & \multicolumn{2}{|c|}{$\operatorname{chi} 2(01)=1624.98$} & \multicolumn{2}{|c|}{ Prob $>$ chi $2=0.000$} \\
\hline
\end{tabular}


Tesadüfi etkili modelin sonuçları incelendiğinde, ilk satırda verilen LR Testi sonucuna göre elde edilen modelin genel olarak anlamlı olduğu görülmektedir. Son satırda verilen LR Testi ise yine birim etkinin anlamlılığını test etmek amacıyla uygulanmıştır. Test sonucunda birim etkisine ait standart sapmanın olmadığını ifade eden sıfır hipotezi reddedilmiş ve modelde birim etkilerin anlamlı olduğu tespit edilmiştir. Sabit etkili modelin sonuçlarına benzer olarak, kontrol değişkenlerinden devlet harcamaları ile cari işlemler dengesi yaşam memnuniyeti üzerinde anlamlı ve pozitif bir etkiye sahipken, işsizlik ise anlamlı ve negatif bir etkiye sahiptir.

Ekonomik büyüme oranı değişkeni incelendiğinde, elde edilen sonuçların sabit etkili model sonuçlarına benzer olduğu görülmektedir. Buna göre en uygun kesirli polinomiyal model, sabit etkili modelde olduğu gibi yine FP2(GDP,3,3) modelidir ve dolayısıyla ekonomik büyüme ile yaşam memnuniyeti arasındaki ilişki kübik - logaritmik bir yapıdadır.

Hem sabit hem de tesadüfi etkili modelde aynı kesirli polinomiyal yapı elde edilmiştir. Dolayısıyla ekonomik büyüme ile yaşam memnuniyeti ilişkisinin bu yapıda olduğu netleşmiştir. Ancak hangi modelin daha uygun olduğunu tespit etmek amacıyla daha önce açıklanan model seçim prosedürü uygulanmıştır. Model seçiminde, klasik panel veri modellerinde seçim için kullanılan Hausman Testi yerine bu prosedürün uygulanmasının nedeni, kesirli polinomiyal yapıyı dikkate almaktır. En uygun modele karar vermek için, her iki modelin logaritmik olabilirlik oranı alınarak sapma miktarları hesaplanmış ve Tablo 3'de sunulmuştur.

Tablo 3. Model Seçim Sonuçları

\begin{tabular}{c} 
Sapma: $D=-2 * \log$ olabilirlik \\
\hline$D_{-}$sabit $=-2 *(-166.01582)=332.03164$ \\
$D \_$tesadüfi $=-2 *(-453.10947)=906.21894$
\end{tabular}

Tabloda yer alan sonuçlara göre, sabit etkili modelin sapma değeri daha düşük olduğundan en uygun model sabit etkili kesirli polinomiyal panel veri modelidir ve bu model sonuçları yorumlanacaktır. Sabit etkili model sonuçlarına göre, belirlenmek istenen ilişkinin grafiği Şekil 1'de verilmiştir. 


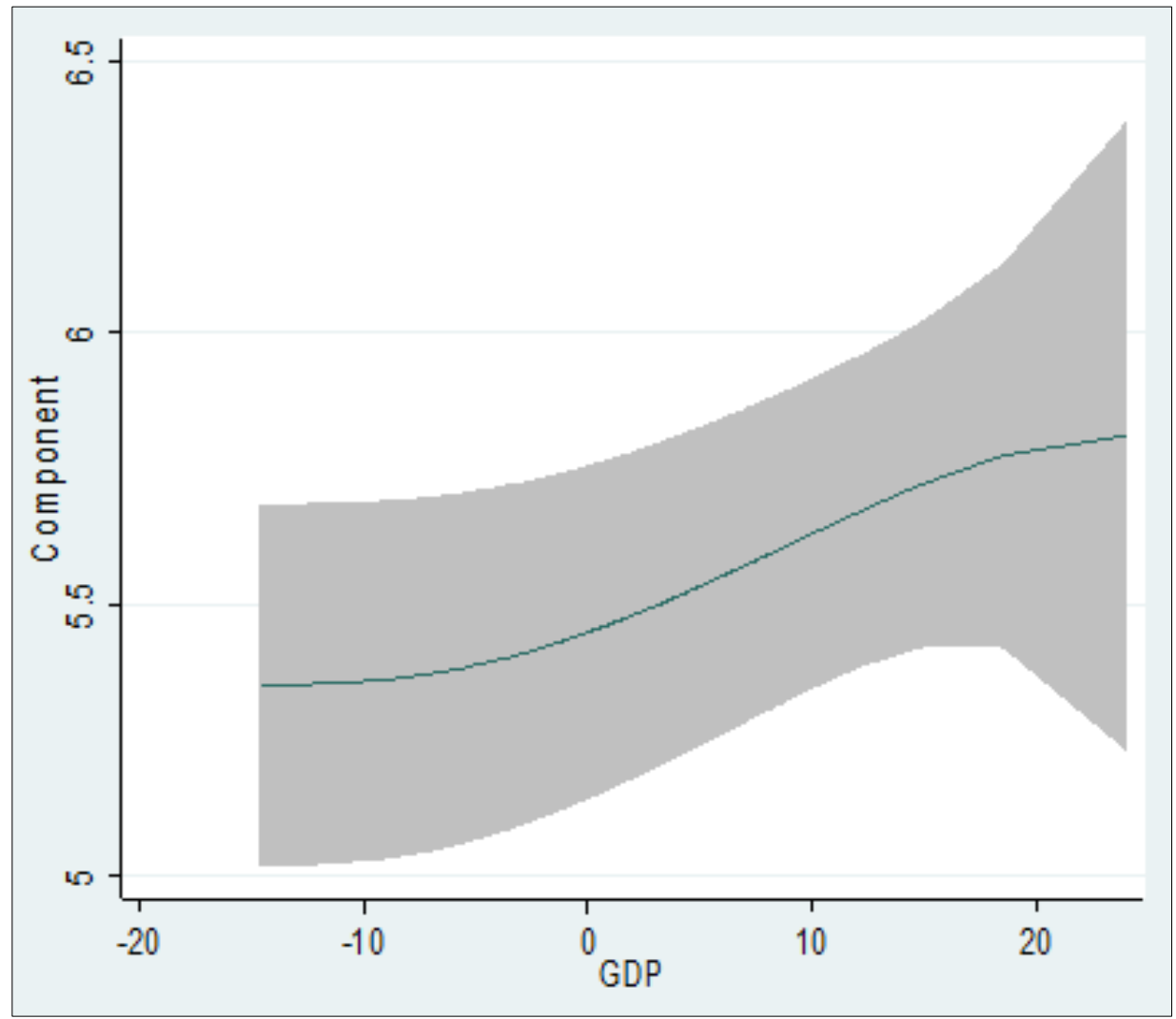

Şekil 1. Ekonomik Büyüme - Yaşam Memnuniyeti İlişkisi

Grafik incelendiğinde, öncelikle ekonomik büyüme ile yaşam memnuniyeti arasında makro düzeyde doğrusal olmayan bir ilişkinin var olduğu görülmektedir. Bir başka deyişle ülkelerin ekonomik büyüme oranı ve dolayısıyla bireylerin gelir düzeyi arttıkça, ortalama yaşam memnuniyeti doğrusal olarak artmamaktadır. Easterlin Paradoksu bu ilişkinin logaritmik olduğunu varsaymaktadır. Yani ekonomik büyüme arttıkça yaşam memnuniyetinin önce artarken daha sonra bu artış hızının yavaşlayarak sabit hale geleceği düşünülmektedir. Elde edilen grafiğe göre, incelenen ilişki sigmoid bit yapıdadır. İlişkiyi düşük ve yüksek büyüme oranları için parça parça yorumlamak daha uygun olacaktır. Buna göre düşük ve orta büyüme düzeylerinde ilişki logaritmik olmaktan ziyade üssel yapıdadır. Düşük ve negatif büyüme oranına sahip ülkelerde, büyüme oranı bir noktaya kadar yaşam memnuniyetini daha az etkilerken, özellikle pozitif büyüme oranına geçtikten sonra, büyümenin yaşam memnuniyeti üzerinde hızlı bir arttırıcı etki gösterdiği görülmektedir. Büyüme oranı artarken, yaşam memnuniyeti düzeyi de bir yere kadar üssel olarak hızla artmaktadır. Ancak yüksek büyüme oranlarına 
gelindiğinde, bu artışın ivme kaybetmeye başladığı görülmektedir. Ortalama \% 10 büyüme oranından sonra ilişkinin logaritmik yapıya benzemeye başladığı söylenebilir. Bir başka deyişle yüksek ekonomik büyüme oranına sahip ülkelerde, kişi başına düşen gelirin artması bir noktadan sonra bireylerin yaşam memnuniyetini daha az arttırmaktadır. Bu durumda yüksek büyüme oranına sahip ülkelerde Easterlin Paradoksunun geçerli olmasının daha muhtemel olduğu söylenebilir. Ancak, çok yüksek büyüme oranlarında eğrinin eğimi azalmasına rağmen sabit hale gelmediği görülmektedir. Buna göre, paradoksta varsayılanın aksine büyümenin yaşam memnuiyeti üzerindeki etkisi yavaş bir artış göstermesine rağmen bir düzeyde sabitlenmez.

Grafiği genel olarak yorumlamak gerekirse, özellikle sadece pozitif büyüme oranına sahip ülkeler ele alındığında, kabaca bir yorumla ilişkinin logaritmik bir yapıya benzediği düşünülebilir. Dolayısıyla klasik regresyon yaklaşımları ile bu ilişki için elde edilebilecek en yakın form logaritmik form olduğundan, daha kaba analizlerle yapının logaritmik olduğu ve Easterlin Paradoksunun geçerli olduğu düşünülebilir. Ancak bu noktada kesirli polinomiyal modellerin kullanımı, daha detaylı bir yapı elde etme imkanı vermiş ve logaritmik yapıya benzeyen bu ilişkinin tam anlamıyla logaritmik olmadığının anlaşılmasını sağlamıştır. Burada negatif büyüme oranına sahip ülkelerin analize dahil edilmesi de etkili olmuştur. Sonuç olarak düşük büyüme oranlarında ilişki üssel bir yapıdadır ve Easterlin Paradoksu geçerli değildir. Yani kişi başına gelir düzeyi düşük olan ülkeler büyümelerini arttırdıkça, vatandaşlarının yaşam memnuniyeti hızla artacaktır. Yüksek büyüme oranına sahip ülkelerde ise ilişki Easterlin Paradoksuna yakın bir yapı göstermektedir. Yani ülkelerin büyüme oranı çok yükselmeye başladığında bireylerin yaşam memnuniyeti önce hızlı bir şekilde artmaya başlarken bir noktadan sonra yavaşlamaya başlayacak ve kişi başına gelirin artışı yaşam memnuniyetini eskisi kadar arttırmayacaktır.

\section{SONUÇ}

Yaşam memnuniyetinin en temel belirleyicilerinden biri gelirdir. Bireylerin gelir düzeyi arttıkça, zorunlu temel ihtiyaçlarına ve diğer bireysel isteklerine ulaşma imkanı artacağından, yaşamlarından daha fazla memnun olacakları düşünülmüştür. Ancak Easterlin Paradoksu, bu varsayımın her zaman geçerli olmadığını ortaya koymaktadır. Gelir düzeyinin artışı bir noktaya kadar yaşam memnuniyetini arttırsa da, bir noktadan sonra bu etki azalacak ve gelir artmaya devam etse bile yaşam memnuniyeti düzeyi artık değişmemeye başlayacaktır. Bireylerin öncelikli istek ve ihtiyaçları genel olarak yüksek gelirle ulaşılabilecek talepler olsa da, bir noktadan sonra Maslow'un ihtiyaçlar hiyerarşisinin üst basamaklarına doğru gelindiğinde, artık ulaşılmak istenen hedefler doğrudan gelire bağımlı olmayacaktır. 
Aralı 2021 Cilt 23 Sayı 2 (533-550)

Gelir ile yaşam memnuniyeti ilişkisi makro düzeyde ele alınmak istendiğinde, gelir yerine ülkeler için kişi başına milli gelirdeki artışın, yani ekonomik büyüme oranının kullanılması uygun olacaktır. Yaşam memnuniyeti için ise ülkenin ortalama yaşam memnuniyeti düzeyi uygun bir göstergedir. $\mathrm{Bu}$ çalışmada Easterlin Paradoksunun makro düzeyde geçerli olup olmadığ 1 araştırılmıştır. $\mathrm{Bu}$ amaçla panel verilerden yararlanılmış, böylece hem oldukça geniş bir ülke grubu ele alınırken, hem de zamana göre değişimin dikkate alınması mümkün olmuştur. Literatürde yer alan çalışmalardan farklı olarak, ilişkinin yalnızca logaritmik olup olmadığını incelemek yerine, logaritmik yapıyı da içeren geniş bir aileden en uygun yapıyı elde etme imkanı sağlayan kesirli polinomiyal modellerden faydalanılmıştır. Bu yöntem, ilişkiyi doğrudan doğrusal veya logaritmik kabul etmek yerine, bu yapıları ve kesirli kuvvetleri de içeren en azından 36 farklı parametrik ilişki yapısını test etmekte ve en uygun yapıyı bulmayı mümkün kılmaktadır. Bu çalışmada kesirli polinomiyal modeller aynı zamanda özgün bir şekilde panel veri modellerinin içine entegre edilmiştir. Böylece hem panel verilerin hem de kesirli polinomiyal modellerin avantajları bir araya getirilmiştir. Bundan faydalanılarak, Easterlin Paradoksunun geçerliliği çok geniş bir ülke grubu için, zamana göre değişim de dikkate alınarak, en uygun fonksiyonel şeklin belirlenmesiyle test edilmiştir.

Çalışmanın sonuçları incelendiğinde, incelenen dönemde ele alınan ülkeler için ekonomik büyüme ile yaşam memnuniyeti arasında kübik - logaritmik bir ilişkinin var olduğu, yani ilişkinin sigmoid bir yapıda olduğu tespit edilmiştir. Buna göre düşük ve orta büyüme oranına sahip ülkelerde ilişki üssel bir yapıdayken, yüksek büyüme oranına sahip ülkelerde ilişki logaritmik yapıya benzemeye başlamaktadır. Bir başka deyişle ekonomik büyüme oranı düşük olan ülkelerde, kişi başına düşen gelir düzeyi arttıkça ortalama yaşam memnuniyeti bir noktaya kadar hızla artmaktadır. Ancak ekonomik büyüme düzeyi belli bir noktaya ulaştıktan sonra bireylerin gelirlerindeki artış yaşam memnuniyetini daha az etkilemeye başlamaktadır. Kaba bir yaklaşımla, pozitif büyüme oranına sahip ülkelerde paradoksun geçerli olduğu çıkarımı yapılabilir olmasına rağmen, kesirli polinomiyal modellerin kullanımı, paradoksun en azından makro düzeyde tam olarak geçerli olmadığını, gelirin memnuniyet düzeyini bir noktaya kadar hızla arttırdığını, daha sonra etkisini kaybetmeye başlasa da sabitlenmediğini ortaya koymuştur. Çalışmada önerilen kesirli polinomiyal modeller yöntemi, paradoksun mikro ölçekte geçerli olup olmadığını, yani bir ülkenin bireyleri için gelir mutluluk ilişkisini incelemek amacıyla da kullanılabilir. 


\section{KAYNAKÇA}

Ambler, G., \& Royston, P. (2001). "Fractional Polynomial Model Selection Procedures: Investigation of Type I Error Rate". Journal of Statistical Computation and Simulation, 89-108.

Blanchflower, D. G., \& Oswald, A. J. (2004). "Well-Being over Time in Britain and the USA". Journal of Public Economics. 88. 1359-1386.

Caporale, G.M., Georgellis, Y., Tsitsianis, N. \& Yin, Y.P. (2009). "Income and Happiness Across Europe: Do Reference Values Matter?". Journal of Economic Psychology. 30. 42-51.

Çirkin, Z., \& Göksel, T. (2016). "Mutluluk ve Gelir”. Ankara Üniversitesi SBF Dergisi. 71:2. 375-400.

Diener, E. (1984). “Subjective Well-Being”. Pyschological Bulletin. 95:3. 542-575.

Easterlin, R.A. (1974). "Does Economic Growth Improve the Human Lot? Some Empirical Evidence". Nations and Households in Economic Growth, Essays in Honor of Moses Abramovitz. 89-125.

Easterlin, R.A. \& Angelescu, L. (2009). "Happiness and Growth the World Over: Time Series Evidence on the Happiness-Income Paradox". IZA Discussion Paper (4060). 1 -29 .

Frey, B.S., \& Stutzer A. (2002). "What Can Economists Learn from Happiness Research”. Journal of Economic Literature. 40. 402-435.

Güriş, S., \& Kızılarslan, Ş. (2018). "Dengesiz Panel Veri Modelleri”. içinde S. Güriş (Ed.), Uygulamalı Panel Veri Ekonometrisi (s. 415-432). İstanbul: Der Yayınlar1.

Köksal, O., \& Şahin F. (2015). "Gelir ve Mutluluk: Gelir Karşılaştırmasının Etkisi". Sosyoekonomi. 23:26. 45-59.

Maslow, A. H. (1943). “A Theory of Human Motivation”. Psychological Review. 50:4. 370-96.

Royston, P., \& Altman D. G. (1994). "Regression Using Fractional Polynomials of Continuous Covariates: Parsimonious Parametric Modelling”. Applied Statistics. 43. 429467.

Royston, P., \& Altman, D. G. (1995). "Using Fractional Polynomials to Model Curved Regression Relationships". Stata Technical Bulletin. 4: 21, 11 - 23.

Royston, P., \& Sauerbrei, W. (2008). Multivariable Model-Building: A Pragmatic Approach to Regression Analysis Based on Fractional Polynomials for Modelling Continuous Variables. Chichester: John Wiley \& Sons.

Sauerbrei, W., \& Royston, P. (1999). "Building Multivariable Prognostic and Diagnostic Models: Transformation of the Predictors by Using Fractional Polynomials". Journal of the Royal Statistical Society. Series A. 71 - 94.

Stevenson, B., \& Wolfers, J. (2008). "Economic Growth and Subjective Well-Being: Reassessing the Easterlin Paradox". Brookings Papers on Economic Activity, Economic Studies Program, The Brookings Institution. 39:1. 1-102.

Veenhoven, R. \& Dumludağ, D. (2015). "İktisat ve Mutluluk". Iktisat ve Toplum Dergisi. 58. 46-51.

World Happiness Report (2019). https://worldhappiness.report/ed/2019/ (Erişim Tarihi: 30.10.2019). 